\title{
Applying Charge Discrimination with Electrospray Ionization-Mass Spectrometry to Protein Analyses
}

\author{
Joseph A. Loo \\ Parke-Davis Pharmaceutical Research, Division of Warner-Lambert Company, Ann Arbor, Michigan, U.S.A.
}

Rachel R. Ogorzalek Loo

Department of Biological Chemistry, University of Michigan, Ann Arbor, Michigan, U.S.A.

Electrospray ionization with a magnetic sector mass spectrometer and scanning array detector has unique advantages for sensitive analyses of large biomolecules. The ability to discriminate against low charge state ions (smaller peptides, buffers and salts, background ions) allows for detection of more highly charged ions from proteins present at much lower concentration relative to the small ions from buffers and detergents present. Low femtomole detection limits can be achieved for proteins greater than $100 \mathrm{ku}$. The charge discrimination phenomenon is more pronounced for higher charged ions, and especially for large biomolecules. Although the charge distribution for the monomer $(66 \mathrm{ku})$ and dimer (133 ku) species of bovine serum albumin overlap, both species can be ascertained readily in a mixture because the lower charged monomer ions have higher optimum microchannel plate voltages than the higher charged dimer ions. Protein-containing solutions can be analyzed directly by electrospray ionization-mass spectrometry (ESI-MS) with array detection, which eliminates time-consuming separation and sample cleanup procedures. For example, hemecontaining proteins can be tirectly detected from ESI-MS of human blood (hemoglobin) as well as from raw meat juices (hemoglobin and myoglobin). (J Am Soc Mass Spectrom 1995, 6, 1098-1104)

$\mathrm{M}$ ass spectrometry relies on the ability to produce and detect gas-phase ions from molecules. In an ideal scenario, the detector's measured response for each type of ion is proportional to the absolute amount of the substance present in the sample. This method works best if the dynamic range required is not large and if no interferences are present. However, because a perfect world rarely exists, the substance the analyst is more frequently asked to identify is present only in very small quantities and constitutes only a small fraction of the total material. To make matters more difficult, the "other" substances present may interfere with its detection, either by chemical suppression, overlapping mass, and so forth. This "needle in a haystack" problem is common. Methods to overcome the dilemma include separation methods (e.g., chromatography, electrophoresis) and various modes of tandem mass spectrometry. We [1] and others [2-5] have found methods to perform selective detection with electrospray ionization (ESI) based

Address reprint requests to Dr. Joseph A. Loo, Parke-Davis l'harmaceutical Research, Division of Warner-Lambert Company, 2800 Ply mouth Road, Ann Arhor, MI 48105 on analyte charge state, much like probing for the metal needle with a magnet.

Electrospray ionization has extended the applicability of mass spectrometry to large biomolecule analyses of over $150 \mathrm{ku}$ [6-9]. Both molecular mass and detection sensitivity have been extended upon the introduction of electrospray ionization-mass spectrometry (ESI-MS) for biochemical analyses [10]. Consumption of low femtomole amounts of protein for molecular weight determination has been demonstrated with most types of mass spectrometric arrangements. We present results and applications that demonstrate the unique characteristics of a position- and time-resolved ion counting (PATRIC) scanning array detector for ESI detection $[1,11]$. The combination of the overwhelming propensity of electrospray ionization to produce multiply charged ions and the PATRIC array detector's ability to discriminate against ions based on charge allows for detection of proteins to the low attomole level. In general, the larger the protein mass, the greater the average charge state observed in ESI mass spectra [6, 12]. Direct detection of higher charged protein molecules in the presence of much higher concentration-lower molecular weight contaminants is possible because of this charge discrimination capability. 


\section{Experimental}

The mass spectrometer used for this study is a Finnigan MAT 900Q double focusing hybrid (EBqQ) mass spectrometer (Bremen, Germany). The instrument is equipped with a $20-\mathrm{kV}$ conversion dynode-secondary electron multiplier (SEM) point detector and a PATRIC focal plane detector after the magnet and before the tandem quadrupole section $[1,13]$. Switching between the two detectors is done electronically and can be performed in less than $0.5 \mathrm{~s}$. A pair of deflector plates after the magnet is used to deflect the ion beam to the array detector mounted underneath the SEM detector. For operation with the PATRIC detector, the maximum $8 \%$ mass-to-charge range of the mass-to-charge ratio centered on the detector was used. The voltage across the front and back of the dual microchannel plates is designated as $V_{\mathrm{MCP}}$. Mass spectra were acquired with full accelerating potential $(5 \mathrm{kV})$ and a scan time of $10 \mathrm{~s}_{\text {decade }}{ }^{-1}$.

The electrospray ionization interface on the system is based on a heated glass capillary inlet developed by Fenn and co-workers [14, 15]. Desolvation of the highly charged droplets is accomplished by a countercurrent stream of warm nitrogen gas $\left(2-5 \mathrm{~L} \mathrm{~min}^{-1}, \sim 60^{\circ} \mathrm{C}\right)$ and by energetic collisions in the electrospray interface controlled by the voltage difference between the tube lens at the metalized exit of the glass capillary and the first skimmer element $\left(\Delta V_{\mathrm{TS}}\right)$. A coaxial stream of $\mathrm{SF}_{6}$ (10-20 $\left.\mathrm{mL} \mathrm{min}^{-1}\right)$ is used to suppress corona discharges. Samples were prepared in the appropriate solvent and buffer systems and infused through the ESI source with a syringe pump at a flow rate of $0.5-1.5 \mu \mathrm{L} \min ^{-1}$.

For the human blood analyses, a single drop of blood was collected in a $1.5-\mathrm{mL}$ eppendorf centrifuge tube and diluted with $100 \mu \mathrm{L}$ of 2:1 methanol-water with $2.5 \%$ acetic acid $(\mathrm{v} / \mathrm{v})$. The solution was sonicated for $15 \mathrm{~min}$ to lyse the red blood cells. A portion of the solution was further diluted by a factor of 10 with the methanol-water-acetic acid solution for the ESI-MS experiments.

Pork juice was obtained from a 1.5-lb package of pork tenderloin purchased $\left(\$ 3.99 \mathrm{lb}^{-1}\right)$ from a local grocery store. The fluid $(0.5 \mathrm{~mL})$ was diluted by a factor of 3 with acidified 2:1 methanol-water, sonicated for $15 \mathrm{~min}$, and centrifuged at high speed for 1 $\mathrm{min}$ to separate the gel-like material from the liquid phase; $10 \mu \mathrm{L}$ of the supernatant was diluted to $1 \mathrm{~mL}$ with the acidified 2:1 methanol-water solution for electrospray-mass spectrometry analysis.

\section{Results and Discussion}

\section{PATRIC Array Performance}

The PATRIC detector's ability to discriminate ions based on charge is a result of its readout mechanism for position sensing $[1,11]$. Position sensing relies on the ratio of pulse heights measured at two electrodes. The pulses arise from the secondary electron cloud generated by an ion that impinges onto the surface of the first of two microchannel plates (MCPs). The gain of the chevron dual MCP is $10^{6}$ at a $V_{\mathrm{MCP}}$ of $\sim 900 \mathrm{~V}$ per plate, yielding $10^{6}$ electrons for each singly charged ion detected. The readout mechanism is designed to handle electron clouds of $10^{4}-10^{6}$ electrons per event, a suitable range for ion counting applications. If the number of electrons is above or below this level, the determination of pulse heights would be less reliable, either by saturating the analog-to-digital conversion (too many electrons) or by having insufficient precision (too few electrons). When either of these extremes is detected by the PATRIC electronics, the according event is discarded.

The secondary electron yield of the microchannel plates does not vary enough to show any noticeable difference in gain between ions that have only one or a few charges. However, for highly charged ions with very high kinetic energy, so many secondary electrons are released upon their impact that more than $10^{6}$ electrons per ion strike the collector plate at the normal operating value for $V_{\mathrm{MCP}}$. Hence, the PATRIC electronics do not register these events as valid (see Figure $1)$. To detect highly charged ions, either $V_{\mathrm{MCP}}$ or the number of primary ions must be reduced so the number of secondary electrons also is reduced. This behavior leads to different optimum operating conditions for detection of low and highly charged ions.

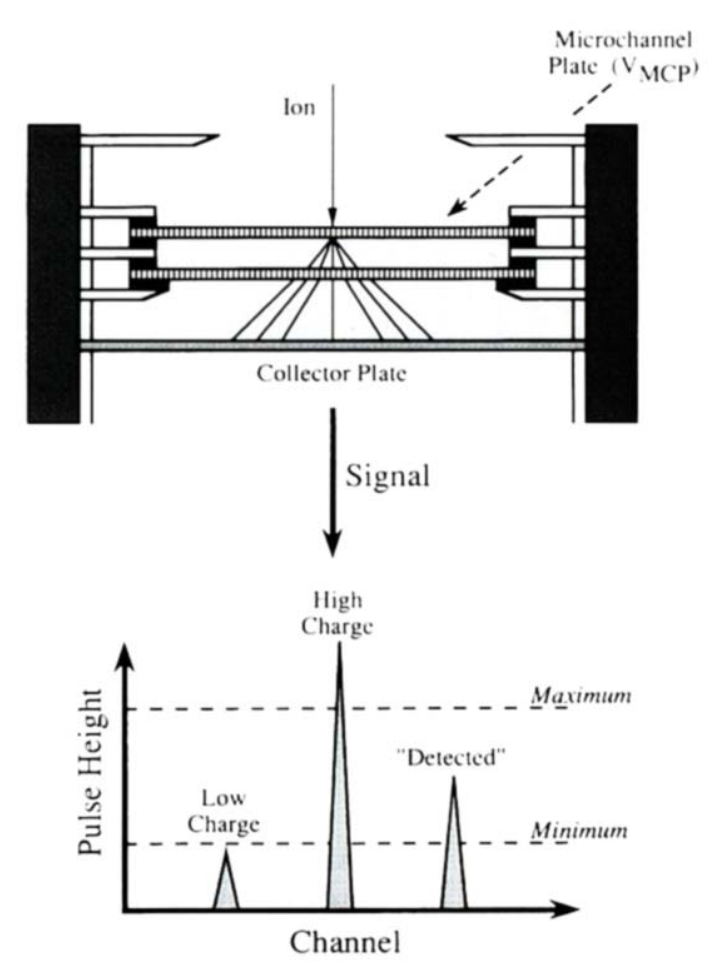

Figure 1. Schematic of the principles behind the operation of the PATRIC detector and its ability to discriminate against ion charge state. 
For example, Figure 2 shows mass spectra at different $V_{\mathrm{MCP}}$ values for $\beta$-galactosidase $(116 \mathrm{ku})$. No resolved protein ions were detected at $V_{\mathrm{MCP}}=+750$ $\mathrm{V}$; only a series of singly charged ions that differ in mass by $342 \mathrm{u}$ was observed (Figure $2 \mathrm{a}$ ). The electrospray ionization mass spectrum of $\beta$-galactosidase at $V_{\mathrm{MCP}}=+610 \mathrm{~V}$ shows resolution of multiply charged ions with over $130+$ charges (Figure 2b). Slightly higher charging was observed at $V_{\mathrm{MCP}}=+590 \mathrm{~V}$, the lowest $V_{M C l}$, value used for any protein analyzed for this study in which ions were detected. Again, in general, the larger the protein, the higher the maximum charge state observed in ESI mass spectra [6, 12]. Consequently, analysis of larger proteins favors lower $V_{\mathrm{MCP}}$ operating values.

The number of secondary electrons generated also can be reduced by reduction of the number of primary ions allowed to strike the array detector. Figure 3 shows mass spectra for a signal transduction protein that plays a critical role in bacterial nitrogen regulation, $\mathrm{P}_{11}[16]$. The 112 amino acid $\mathrm{P}_{11}$ protein exists as a $12.4-\mathrm{ku}$ monomer in acidic solution (and a noncovalently bound trimer at $\mathrm{pH}>6)([16]$ and Ogorzalek Loo, R. R.; Andrews, P. C.; Ninfa, A. J.; Loo, J. A., in preparation). At low $V_{\mathrm{MCr}}(+700 \mathrm{~V})$, multiple charging to the $17+$ charge state is observed with a normal shaped-charge distribution. At the same $V_{\mathrm{MCP}}$ but with a wider entrance slit opening to allow more of the primary ion beam to impact the detector, an apparent bimodal charge distribution is observed in the spectrum. The more abundant charge state ions $(11+$ to

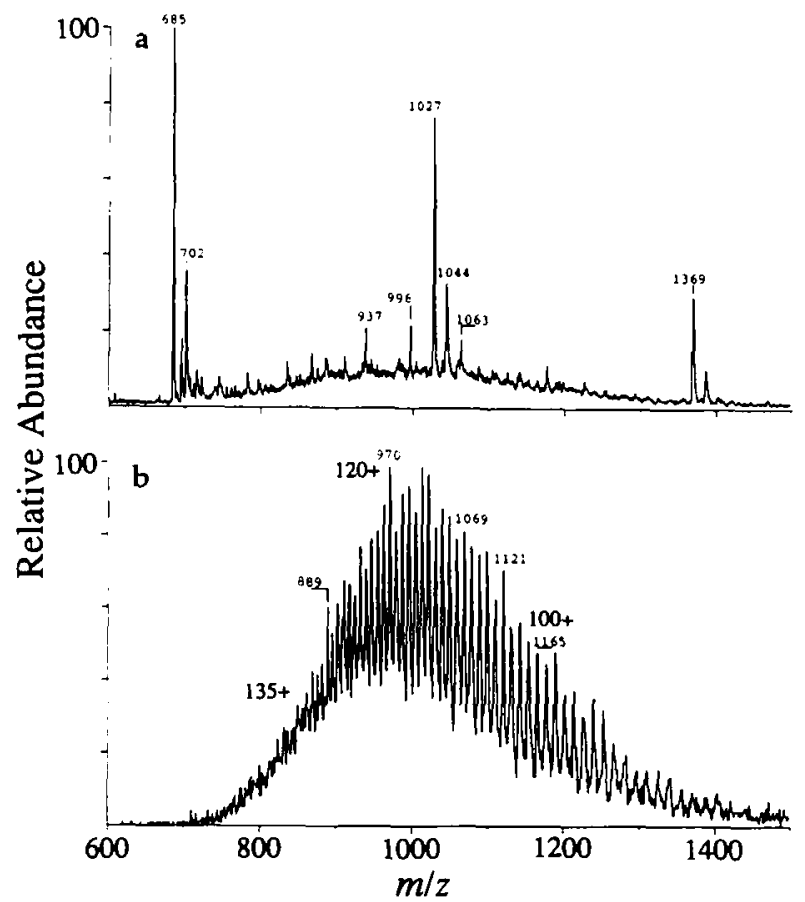

Figure 2. ESI mass spectra of $\beta$-galactosidase ( $116 \mathrm{ku}, 6 \mathrm{pmol}$ $\mu \mathrm{L}^{-1}$ in $2: 1 \mathrm{MeOH}-\mathrm{H}_{2} \mathrm{O}$ with $5 \%$ acetic acid) with $V_{\mathrm{MCP}}$ at (a) $+750 \mathrm{~V}$ and $(\mathrm{b})+610 \mathrm{~V}$
$14+$ ) have saturated the detection electronics, which decreases the ability of the detector to register the events and produces the odd-shaped charge distribution. Further lowering of the array detector voltage would reduce this artifact.

Previously, we demonstrated low attomole detection limits under scanning conditions for small proteins such as ubiquitin $(8.5 \mathrm{ku})$ [1]. Other protein results obtained over the course of this study with the PATRIC array detector are collected in Table 1. A spectrum from approximately $75 \mathrm{fmol}$ of material consumed for the myoglobin-heme noncovalent complex with $V_{\mathrm{MCP}}=850 \mathrm{~V}$ has been published previously [17]; lowering the $V_{\mathrm{MCP}}$ improved the detection limit by a factor of 7 (Table 1). No special protocols were used to handle such dilute protein solutions. By using lower $V_{\mathrm{MCP}}$ voltages, highly charged protein molecules are preferentially detected over lower charged background ions. The data in Table 1 were determined at the level at which the most abundant multiply charged protein ion has a signal-to-noise ratio greater than 5 . The signal-to-noise ratio was estimated by using the absolute intensity level of the most abundant protein peak and two times the standard deviation of the noise intensity over a $40 \mathrm{~m} / \mathrm{z}$ unit region around the protein peak, as described by Cody and co-workers [18]. The table is not meant to provide "benchmark" values for detection limits. For some examples listed in the table, the signal-to-noise ratio is greater than 10 for the lowest analyte concentration studied. For larger proteins (and more highly charged species), the total ana-

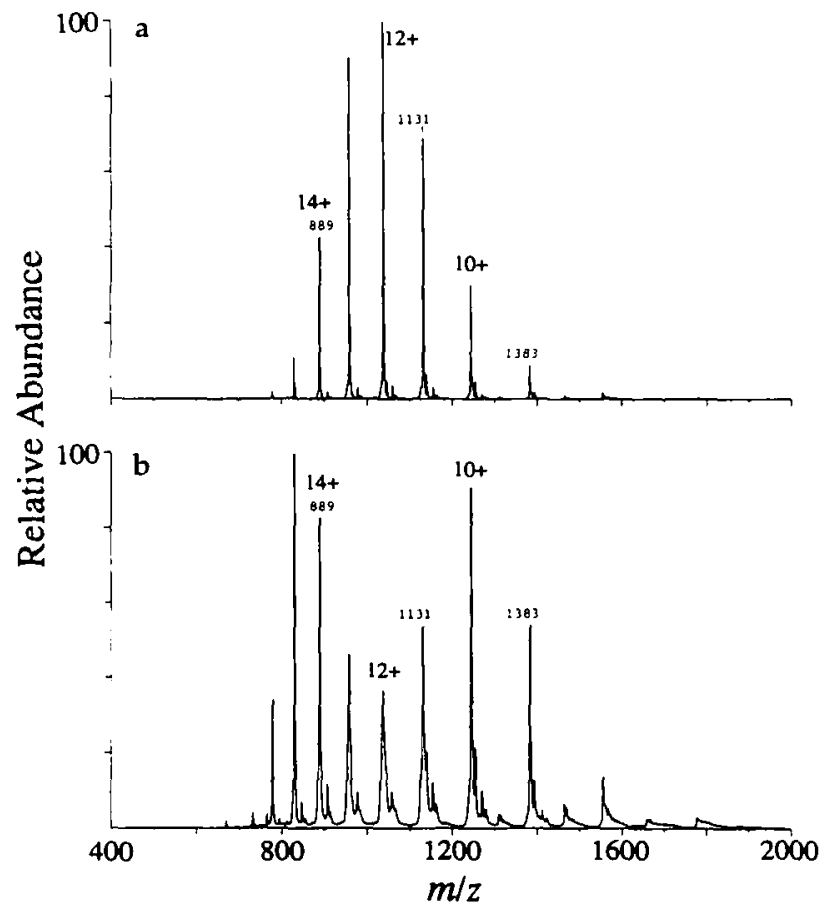

Figure 3. Electrospray ionization mass spectra of $P_{11}$ protein with $V_{\mathrm{MCP}}=+700 \mathrm{~V}$ and the entrance slit set for a resolving power of approximately (a) 8000 and (b) 500 . 
Table 1. ESI-MS detection limits with the PATRIC array detector

\begin{tabular}{|c|c|c|c|}
\hline Protein & $M_{\mathrm{r}}$ & $\begin{array}{c}\text { Concentration }{ }^{a} \\
(\mathrm{fmol} / \mu \mathrm{L})\end{array}$ & $\begin{array}{c}\text { Amount } \\
\text { consumed } \\
\text { (fmol) }\end{array}$ \\
\hline 40 Amino acid peptide & 4,644 & 2.7 & 0.8 \\
\hline Bovine ubiquitin & 8,565 & 0.3 & $<0.09$ \\
\hline Equine cytochrome $c$ & 12.360 & 0.3 & 0.3 \\
\hline Equine myoglobin ${ }^{c}$ & 17.567 & 140 & 12.0 \\
\hline $\begin{array}{l}\text { Bovine carbonic } \\
\text { anhydrase }\end{array}$ & 29,021 & 2.7 & 1.3 \\
\hline Porcine pepsin ${ }^{\prime}$ & 34,600 & 2.5 & 0.5 \\
\hline Bovine albumin & 66.430 & 20.0 & 4.1 \\
\hline$\beta$-Galactosidase & 116,000 & 60.0 & 180 \\
\hline Bovine albumin dimer & 133,000 & 225 & 23 \\
\hline
\end{tabular}

"Analyte solution flow rate $\leq 1 \mu \mathrm{L}$ min 1 .

"Scan range $m / 2400-1800 ; 5 s \operatorname{scan} 1 ;$ signal-to-noise ratio > 5 for most abundant protein ion.

"Noncovalent polypeptide-heme complex

Negative ion ESI-MS.

lyte signal is distributed over more charge states than for smaller peptides and proteins. Therefore, actual "detection" limits should be even lower than those listed in Table 1 if ESI mass spectra are converted from mass-to-charge to the mass scale (i.e., spectral deconvolution).

\section{Discrimination Based on Charge State}

The discrimination behavior of the PATRIC detector is based primarily on charge and not mass. Syage $[19,20]$ previously noted that for ionized atoms (e.g., Ar ${ }^{n+}$, $\mathrm{Kr}^{\prime \prime}$, and $X \mathrm{e}^{\mathrm{n} \cdot}$ ), the secondary electron yields for microchannel plate detectors depend on ion impact energy, which depends on charge state. We have observed the same phenomenon for macromolecules. For example, horse heart cytochrome $c(12.3 \mathrm{ku})$ and hen egg white lysozyme $(14.3 \mathrm{ku})$ are similar mass proteins. Under aqueous solution conditions $(\mathrm{pH} \sim 6)$, the charge state distributions are similar and detection sensitivities respond similarly with varying $V_{\mathrm{MCl}}$ (Figure ta and b). However, under more acidic conditions, the charge state distribution for cytochrome $c$ shifts to higher charge (lower mass-to-charge ratio), whereas the lysozyme charge states remain the same. The higher charged cytochrome $c$ protein ion intensities are optimized at lower $V_{\mathrm{MCr}}$ than for lower charged lysozyme (Figure $4 c$ and $d$ ).

The negative ion ESI mass spectra of porcine pepsin $(34.6 \mathrm{ku})$ at different $V_{\mathrm{MCl}}$, values are shown in Figure 5. Again, lower $V_{\mathrm{MCP}}$ favors detection of the higher charged species. However, a characteristic of ESI spectra for larger mass proteins with the array detector at higher $V_{\mathrm{MCl}}$ is the increasing baseline intensity under the charge distribution and peak broadening. The cause for this is unclear at this moment. The rising baseline may arise from problems in position sensing when
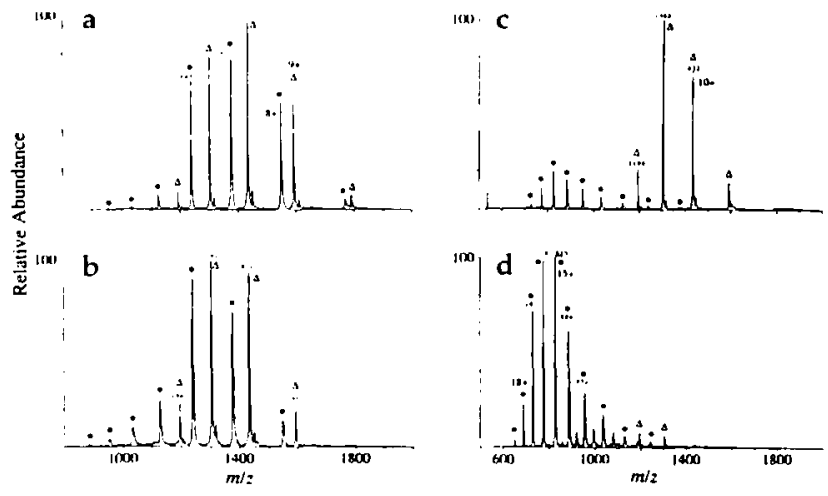

Figure 4. ESI mass spectra of an equimolar mixture of horse cytochrome $i$ (O, $\left.M_{r}=12,360\right)$ and hen lysozyme $\left(\Delta, M_{r}=\right.$ $14,306)$ in $\mathrm{H}_{2} \mathrm{O}$ with $V_{N(1,}$ at $(\mathrm{a})+850 \mathrm{~V}$ and $(\mathrm{b})+675 \mathrm{~V}$ and in $2: 1 \mathrm{MeOH}-\overline{\mathrm{H}}_{2} \mathrm{O}$ with $2.5 \%$ acetic acid and $V_{116}$, at $(c)+900 \mathrm{~V}$ and $(\mathrm{d})+650 \mathrm{~V}$.

more than one ion reaches the detector at the same time. The position- and time-sensitive detector may no longer be counting single ions under those conditions. Peak shapes are broadened because data from the center of the peaks mostly are being discarded. Also, higher $V_{\mathrm{MCl}}$ farors detection of lower charged ions that may be present as contaminants or as solvent clusters.

ESI mass spectra of bovine serum albumin (BSA) "dimer" $(133 \mathrm{ku})$ are shown in Figure 6. At $V_{\mathrm{MCP}}=$ $+625 \mathrm{~V}$, a smooth distribution of multiply charged ions is observed. However, with $V_{\mathrm{NCl}}=+800 \mathrm{~V}$, ad-

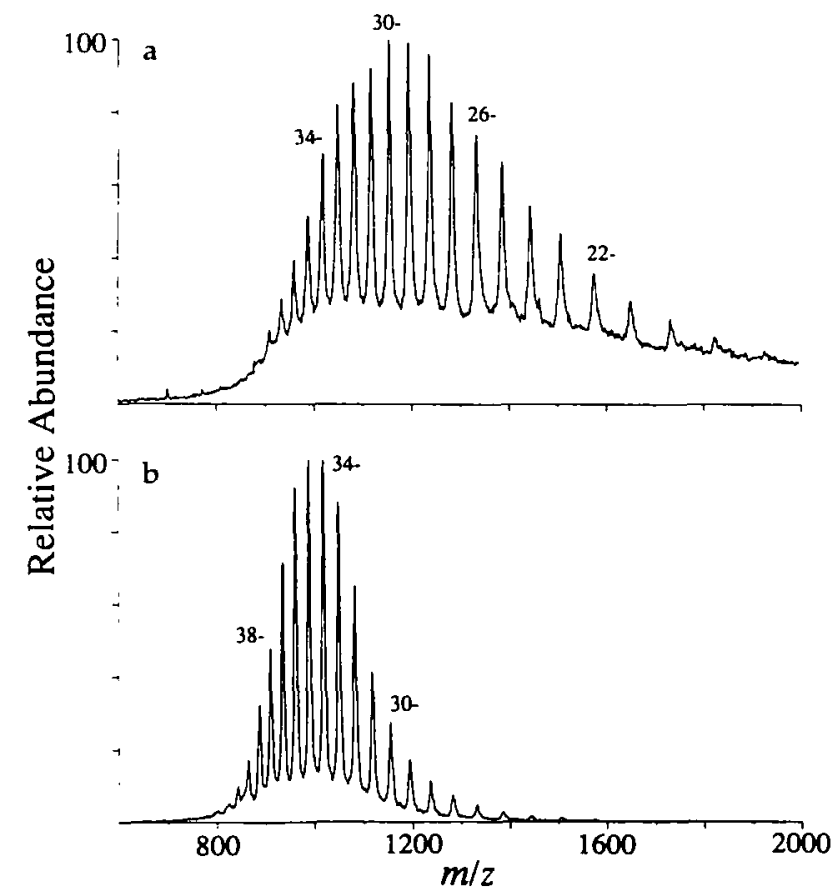

Figure 5. Negative ion mass spectra of porcine pepsin ( $34.6 \mathrm{ku}$, $1: 1 \mathrm{H}_{2} \mathrm{O}-\mathrm{MeOH}$ and $1 \% \mathrm{NH}_{4} \mathrm{OH}$ ) with $V_{\mathrm{MCP}}$ at (a) $900 \mathrm{~V}$ and (b) $725 \mathrm{~V}$. 
jacent peaks alternate in abundance. The presence of BSA monomer $(66 \mathrm{ku})$ in the sample is most likely the cause. The charge distributions for the BSA monomer and dimer ions overlap. In Figure 6, the mass-to-charge ratio value of the $[\mathrm{M}+39 \mathrm{H}]^{34+}$ is the same as the $[2 \mathrm{M}+78 \mathrm{H}]^{78+}$ ion. However, the odd-charged dimer ions do not overlap with the monomer ions. At higher $V_{\mathrm{MCP}}$, the detection of the lower charged-lower mass albumin monomer contaminant is favored. Previously published ESI mass spectra of BSA dimer obtained with a variety of instruments (i.e., quadrupole, magnetic sector, and Fourier transform mass spectrometers) without charge discrimination capabilities did not show the alternating series of ions [6, 21-24].

The discrimination phenomenon is slightly more evident with higher charge state ions and subsequently larger proteins. The average charge state (calculated from the intensity-weighted value from each charge state observed [25]) for 8.5-ku ubiquitin only increases from 9.2 to 10.4 upon decreasing $V_{\text {MCP }}$ from +900 to $+675 \mathrm{~V}$. For $66-\mathrm{ku}$ BSA, the average charge state increases from $43.7\left(V_{\mathrm{MCP}}=+850 \mathrm{~V}\right)$ to $50.8\left(V_{\mathrm{MCP}}=+625 \mathrm{~V}\right)$ (see Figure 7$)$. However, the greatest increase in average charge state for the larger proteins is observed only at the lower $V_{M C P}$ values. The increase in charge state is greatest below $V_{\mathrm{MCP}}=$ $+700 \mathrm{~V}$. To maximize the charge discrimination effect (i.e., detect the highest charged ion), the lowest possible $V_{\mathrm{MCl}}$, should be used.

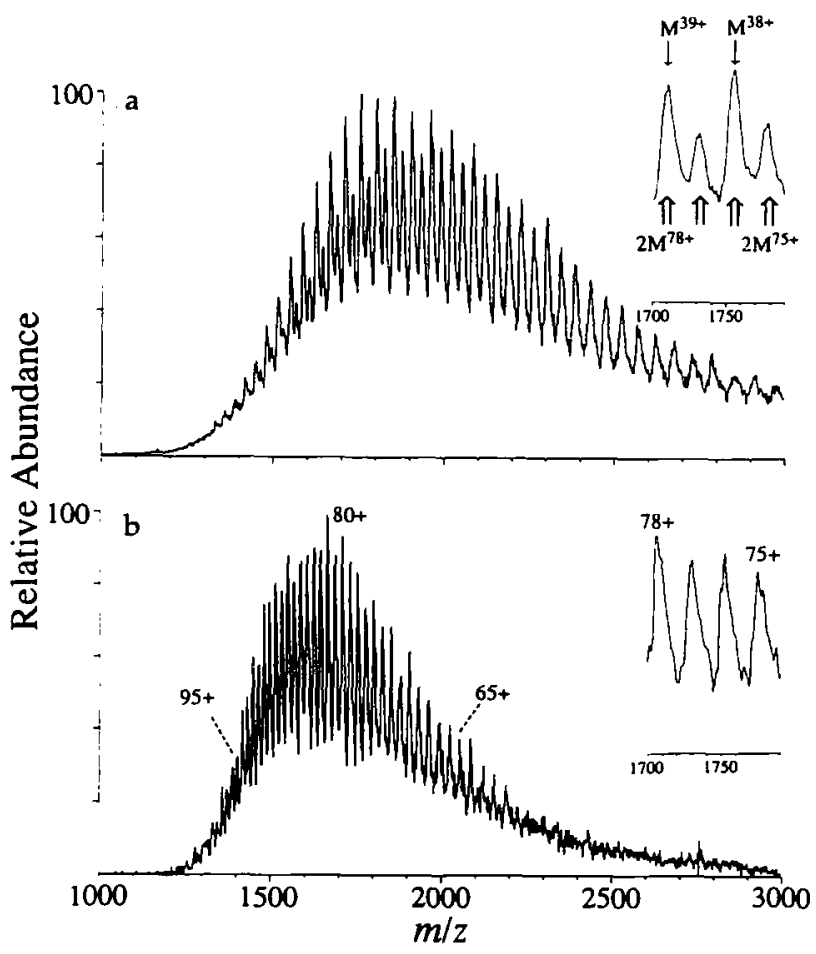

Figure 6. Mass spectra of bovine serum albumin dimer (133 ku) at $V_{\mathrm{MCP}}$, values of (a) $+800 \mathrm{~V}$ and $(\mathrm{b})+625 \mathrm{~V}$. The presence of the albumin monomer $(66 \mathrm{ku})$ is indicated by the alternating abundances in the top figure.

\section{Applications of Charge Discrimination}

The presence of salts and buffers often can be disabling for ESI-MS experiments. A high level of background ions can interfere with detection of the lower amounts of analyte. In addition, the higher ionic strength and solution conductivity can interfere with the electrospray ionization process. However, the advantages of low molecular weight (low charge) discrimination can offset some of these interferences, which allows solutions with high levels of interfering buffers and other additives used in protein chemistry to be analyzed directly by ESI-MS. For example, TWEEN 20 (polyoxyethylene sorbitan monolaurate) is a nonionic detergent often used to solubilize proteins. ESI mass spectra for a 1.6-pmol $\mu \mathrm{L}^{-1}$ solution of plasminogen activator inhibitor protein $(42.8 \mathrm{ku})$ in the presence of TWEEN 20 are shown in Figure 8. A small amount of TWEEN remained in the preparation after extensive dialysis. The mass spectrum with $V_{\mathrm{MCP}}=+850 \mathrm{~V}$ shows only singly charged ions separated by $44 \mathrm{u}$ for the detergent oligomers (Figure 8a); reduction of $V_{\mathrm{MCP}}$ to $+685 \mathrm{~V}$ allows detection of the protein multiply charged molecules only (Figure 8b). Similarly, ESI mass spectra of proteins ( $\left.<10 \mathrm{pmol} \mu \mathrm{L}^{-1}\right)$ in the presence of $50-\mathrm{mM}$ TRIS buffer, Triton X-100 [1], and 4-mM polyethylene glycol (PEG 1000) can be obtained at the lower $V_{\mathrm{MCP}}$ voltages.

Charge discrimination may be used to provide information with regard to the relative charge state of an

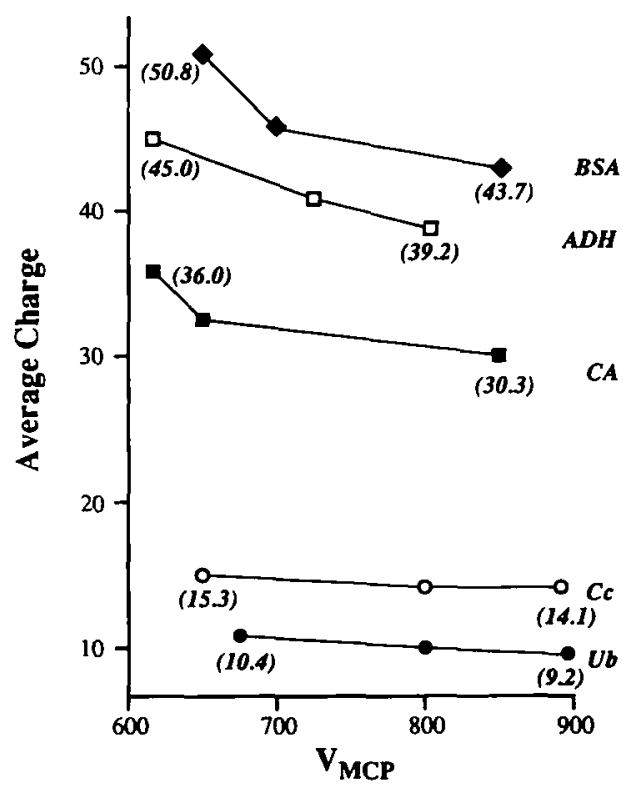

Figure 7. Graph of $V_{\mathrm{MCl}}$, versus observed average charge state for several proteins. The average charge state was calculated from the measured peak heights for each charge state ion (intensity-weighted average). Symbols represent data for bovine ubiquitin $(8.5 \mathrm{ku}, \mathrm{Ub}, 0)$, horse cytochrome $\mathrm{c}(12.4 \mathrm{ku}, \mathrm{Cc}, \mathrm{O})$, bovine carbonic anhydrase (29 ku, CA, - ), horse alcohol dehydrogenase ( $39 \mathrm{ku}, \mathrm{ADH}, \square)$, and bovine serum albumin (66 ku, BSA, ). Some of the average charge state values are indicated on the figure for clarity. 


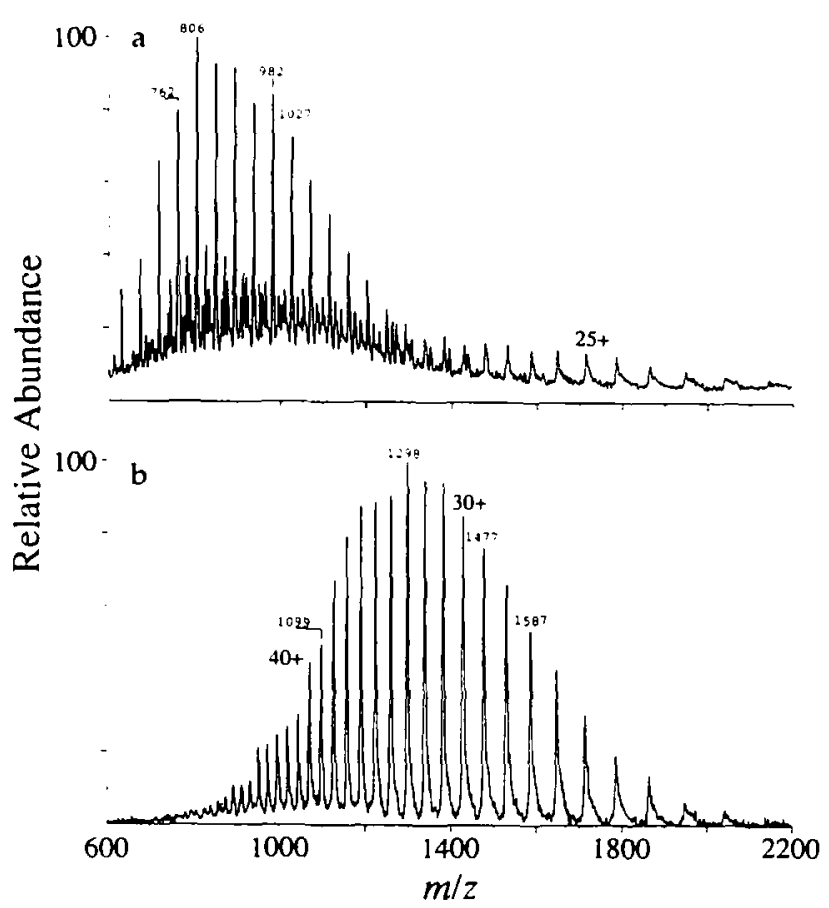

Figure 8. ESI mass spectra of plasminogen activator inhibitor $(+2.8 \mathrm{ku})$ at a $V_{\mathrm{MC}}$, value of $(\mathrm{a})+850 \mathrm{~V}$ and $(\mathrm{b})+685 \mathrm{~V}$. Singly charged ions for TWEEN 20 are observed below $m /=1500$ and multiply charged ions for the protein are observed in the top tigure, whereas only protein ions are observed in the bottom spectrum.

ion, especially for mixture samples. The spectra shown in Figure 9 are from a sample that contains a mixture of cleavage products from thioredoxin protein ( $E$. coli, $11.7 \mathrm{ku}$ ); the principal components arise from selective cleavage between Arg-73 (residues 1-73, $M_{\mathrm{r}}=8063$ ) and Gly-74 (residues 74-108, $M_{\mathrm{r}}=3628$ ) [26]. The region in the spectra around $m /=890-910$ should contain several peaks with different charge states, namely, the $9+$ ion for the protein that represents residues $1-73(m /=897)$ and the $4+$ ion for residues $74-108(m / z 908)$. By varying the array detector voltage, the charge state of the peaks at $m / z 897[(\mathrm{M}+$ $\left.9 \mathrm{H})^{9+}\right]$ and $m / z 901\left[(\mathrm{M}+8 \mathrm{H}+\mathrm{K})^{9+}\right]$ (favored at low $\left.V_{\mathrm{MCl}}\right)$ can be deduced readily to be a higher charge state than the $m /=908$ peak (favored at high $V_{\mathrm{MCP}}$ ). (Interestingly, multiple potassium adducts also were observed in the spectra. Potassium-attached ions are more abundant for the higher charge state ions. For example, the relative abundance of the ion at $m / z 908$ $\left[(\mathrm{M}+8 \mathrm{H}+\mathrm{K})^{9+}\right]$ to the ion at $m / z 897\left[(\mathrm{M}+9 \mathrm{H})^{9+}\right]$ is greater than the $m / \approx 1158\left[(\mathrm{M}+6 \mathrm{H}+\mathrm{K})^{7+}\right] / m / z$ $1152\left[(\mathrm{M}+7 \mathrm{H})^{7+}\right]$ ratio in Figure 9b.) Spectra acquired with a quadrupole mass spectrometer with a conventional multiplier detector are similar to the spectrum acquired at high $V_{M C P}$ (Figure 9a). For this example, mass spectra that show primarily a single protein component can be obtained at the extremes of the $V_{\mathrm{MCr}}$ scale.

The ability to discriminate against low charged background ions allows protein analyses to be carried

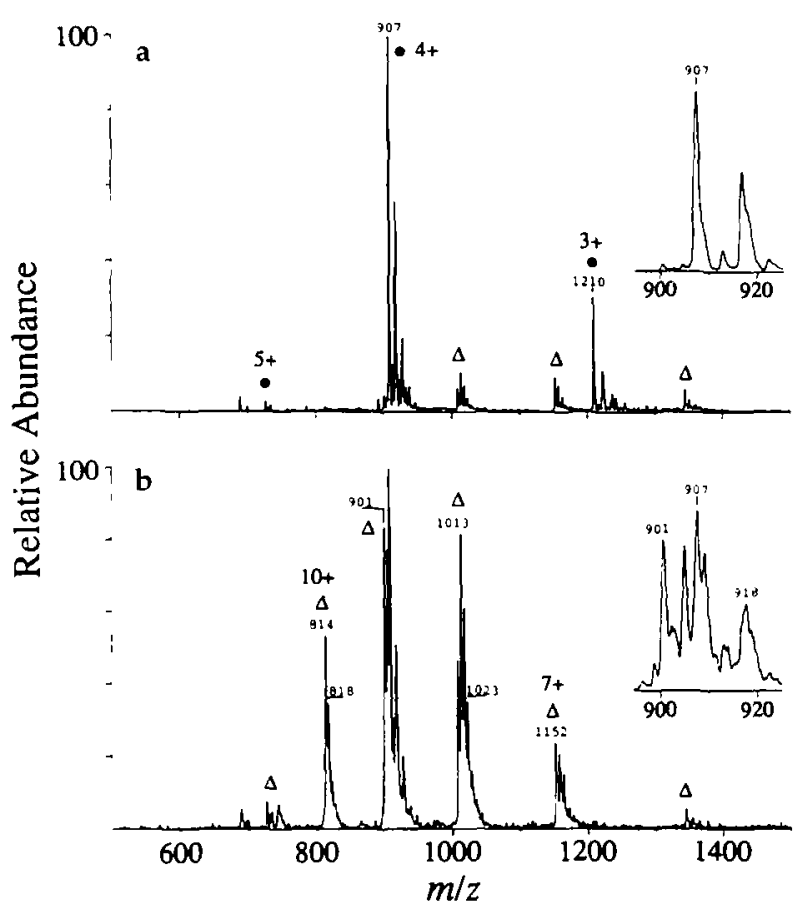

Figure 9. ESI mass spectra of thioredoxin $(11.6 \mathrm{ku})$ fragments (residues $1-73, M_{r}=8063$ and residues $74-108, M_{r}=3628$ ) at a $V_{\mathrm{MC}}$. value of (a) $+875 \mathrm{~V}$ and $(\mathrm{b})+675 \mathrm{~V}$. The $\Delta$ symbol represents peaks for the $1-73$ residue protein.

out with minimal sample cleanup. Hemoglobin $(\mathrm{Hb})$ is the major protein species in blood. Hemoglobin content in adult human blood is approximately $15 \mathrm{~g} \mathrm{dL}^{-1}$, or $9 \mathrm{mM}$ (for the $\mathrm{Hb}$ tetramer) [27]. A spectrum obtained from human blood (from one of the authors) after sonication to lyse the red blcod cells and dilution with the methanol-water-acetic acid ESI solution is shown in Figure 10a. Other than the multiply charged ions for the $\alpha-\left(M_{\mathrm{r}}=15,126\right)$ and $\beta$-chains $\left(M_{\mathrm{r}}=\right.$ $15,867)$ and the singly charged heme ion $(m / \Sigma 616)$, very few other species were observed. The ratio of the [heme $^{+}$]/[protein ${ }^{n+}$ ] (where $n=10-21$ ) ions was observed to increase with increasing $V_{\mathrm{MCP}}$, as expected. The analysis of blood without any sample cleanup introduces little nonprotein contamination and is not particularly challenging. However, blood samples from tissue represent a different situation. The identification of heme-proteins for meat speciation may be an important application of mass spectrometry for the meat industry [28]. Figure 10b shows the ESI mass spectrum taken from a raw pork meat juice "sample" (see Experimental Section). Materials other than blood, such as fats and other possible contaminants such as from the plastic wrappers, were most likely present. However, analysis of the sample at a low $V_{\mathrm{MCr}}$ voltage $(+710 \mathrm{~V})$ revealed readily observable multiply charged ions for the $\alpha-\left(M_{r}=15,039\right)$ and $\beta$-chains $\left(M_{r}=16,035\right)$ of pig hemoglobin and pig apomyoglobin $\left(M_{r}=16,954\right)$. No hemoglobin or myoglobin ions were observed at $V_{\mathrm{MCP}}$ voltages greater than $+800 \mathrm{~V}$ because the broad unresolved background in the spectra interfered with the higher charged protein ions. 

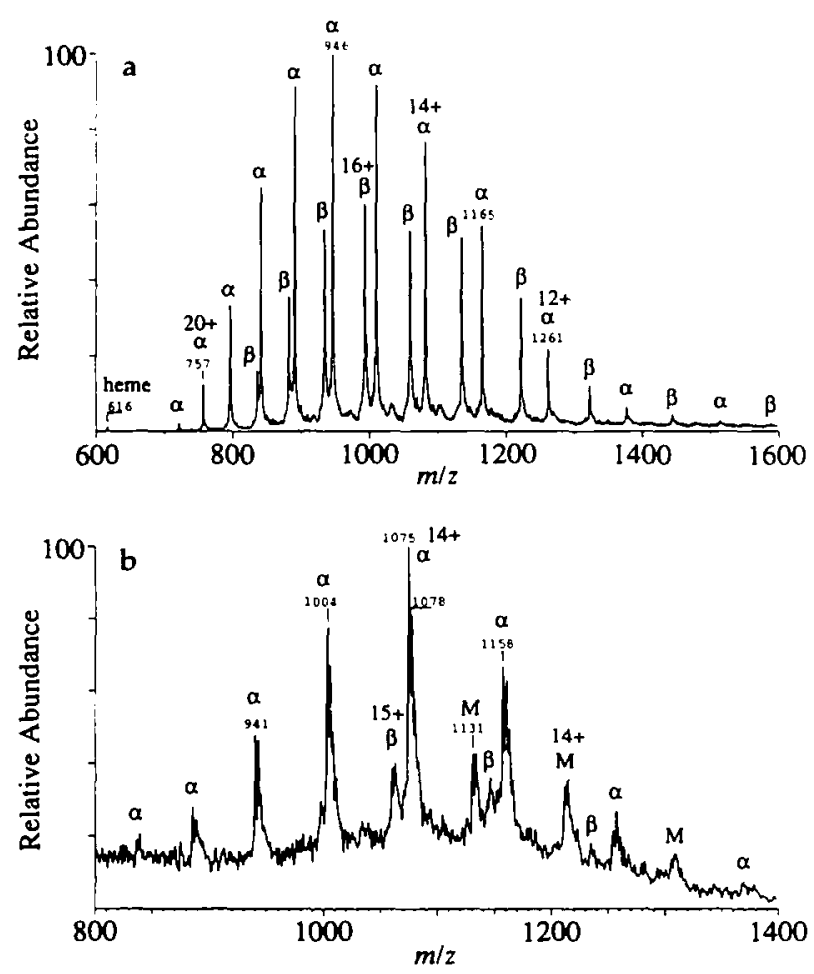

Figure 10. Electrospray ionization mass spectra of hemeproteins directly from (a) human blood and (b) raw pork juice with $V_{\mathrm{MC} P}=+700 \mathrm{~V}$.

\section{Conclusion}

Detection limits of large, multiply charged ions with an array detector that has a pulse height ceiling can be dramatically improved by lowering the ion acceleration energy in the microchannel plate. The ability to discriminate against lower charged species allows one to "tune" a spectrum for a higher charged-low level species in a complex mixture. This is especially useful for electrospray, where the signal intensity for a given analyte is distributed over the entire charge envelope, which thereby reduces the absolute intensity of each multiply charged ion. In a sense, by scanning $V_{\mathrm{MCl}}$, one can perform a crude separation based on charge state with a mass spectrometer. Although the resolving power of the separation is not nearly as high as for typical liquid phase separation methods, the ability to obtain relative charge state information provides a third dimension to the typical ESI mass spectrum.

\section{Acknowledgments}

We thank Dr. Reinhold Pesch (Finnigan MAT) for invaluable help with regard to the theory and performance of the array detector and Dr. Jack Syage (The Aerospace Corporation) for bringing to our attention previous references on detector response as a function of charge state. We also wish to acknowledge Professor Maria Luisa Tasayco (City College of the City University of New York), Dr. Dan Lawrence (University of
Michigan, Ann Arbor, MI), and Professor Alex Ninfa (University of Michigan, Ann Arbor, MI) for the thioredoxin fragments, plasminogen activator inhibitor, and $P_{11}$ protein, respectively Finally, we are grateful for the encouragement the McLaffertys (Fred and Tibby) have given us throughout our careers.

\section{References}

1. Loo, J. A.; Pesch, R. Awal. Chem. 1994, 66, 3659-3663.

2. Axelsson, J.; Reimann, C. T.; Sundquist, B. U. R. Int. I. Malss Spectrom. Ion Processis 1994, 133, 141-155.

3. Feng, R.; Konishi, Y. Proceitings of the 39th ASMS Confireme on Mass Spectrometry and Alliad Topics; Nashville, TN, 1991; pp 260-261.

4. Standing, K. G.; Chernushevich, I.; Ens, W.; Verentehikow, A. Procedings of the 42nd ASMS Conference on Mass Spectrometry and Allied Topics; Chicago, IL, 1994; P 1148.

5. Hofstadler, S. A.; Beu, S. C.; Laude, D. A. Amal. Chrm. 1993, $65,312-316$.

6. Smith, R. D.; Loo, J. A.; Edmonds, C. C.; Barinaga, C. J.; Udseth, H. R. Anul. Clem. 1990, 62, 882-899.

7. Loo, J. A. I. Mass Spictrom. 1995, 1, 180-183.

8. Feng, R.; Konishi, Y. Anit. Clu'm. 1992, 64, 2090-2095.

9. Tang, X.-J.; Brewer, C. F.; Saha, S.; Chernushevich, 1.; Ens, W.; Standing, K. G. Rapid Commum. Mass Spettrom. 1994, 8 , $750-754$.

10. Meng, C. K.; Mann, M.; Fenn, J. B. Z. Phys. D-Atoms, Molecules and Clusters 1988, 10, 361-368.

11. Pesch, R.; Jung, G.; Rost, K.; Tietie, K.-H. Procedings of the 37th ASMS Conforence on Mass Spectronetry and Allid Topics; Miami Beach, FL, 1989; pp 1079-1080.

12. Smith, R. D.; Loo, J. A.; Ogorzalek Loo, R. R.; Busman, M.; Udseth, H. R. Mass Spretrom. Rin. 1991, 11, 359-451.

13. Loo, I. A.; Ogorzalek Loo, R. R.; Andrews, P. C. Org. Mass Spectrom. 1993, 28, 1640-1649.

14. Whitehouse, C. M.; Dreyer, R. N.; Yamashita, M.; Fenn, J. B Anal. Ch'm. 1985, 57, 675-679.

15. Fenn, J. B.; Mann, M.; Meng, C. K.; Wong, S. F.; Whitehouse, C. M. Mass Spectrom. Reis. 1990, 9, 37-70.

16. Cheah, E.; Carr, P. D.; Suffolk, P. M.; Vasudevan, S. G.; Dixon, N. E.; Ollis, D. L. Structure 1994, 2, 981-990.

17. Loo, J. A.; Goordani, A. G.; Muenster, H. Rapit Commun. Mass Spectrom. 1993, 7, 186-189.

18. Cody, R. B.; Tamura, J.; Finch, J. W.; Musselman, B. D. I. Am. Soc. Mass Spectrom. 1994, 5, 194-200.

19. Syage, J. A. I. Phys. B: At. Mol. Opt. Phys. 1991, 24, L527-L532.

20. Syage, J. A. Phys. Rev. A 1992, 46, 5666-5679

21. Loo, J. A.; Udseth, H. R.; Smith, R. D. Anal. Biochm. 1989. 179, 404-412.

22. Chapman, J. R.; Gallagher, R. T.; Mann, M. Biod/'m. Sox. Trans. 1991, 19, 940-943.

23. Chapman, J. R.; Gallagher, R. T.; Barton, E. C.; Curtis, J. M.; Derrick, P. J. Org. Mass Spectrom. 1992, 27, 195-203.

24. Guan, Z.; Hofstadler, S. A.; Laude, D. A., Jr. Anal. Chem. $1993,65,1588-1593$.

25. Mirza, U. A.; Chait, B. T. Anal. Chem. 1994, 66, 2898-2904.

26. Tasayco, M. L.; Chao, K. Proteins: Struct., Funtet., Ge'net. 1995, $22,41-44$.

27. Hardisty, R. M.; Weatherall, D. J., Eds. Bloot and its Disorders; Oxford, U.K.: Blackwell Scientific, 1974.

28. Taylor, A. J.; Linforth, R.; Weir, O.; Hutton, T.; Green, B. Mert Sci. 1993, 33, 75-83. 